\title{
Electroactive Materials for Anion Separation - Technetium from Nitrate
}

(Project Number: 81912)

\section{Principal Investigator}

Timothy L. Hubler

Pacific Northwest National Laboratory

P.O. Box 999, MSIN K8-93

Richland, WA 99352

509-373-0249 (phone)

509-372-2549 (fax)

tim.hubler@pnl.gov

\section{Co-Investigators}

James McBreen

Brookhaven National Laboratory

DAS, Bldg. 480

Upton, NY 11973

631-344-4513 (phone)

631-344-4071 (fax)

jmcbreen@bnl.gov

William H. Smyrl

Corrosion Research Center

Department of Chemical Engineering and Materials Science

University of Minnesota Minneapolis

221 Church Street SE

Minneapolis, MN 55455

612-625-0717 (phone)

612-626-7246 (fax)

smyr1001@maroon.tc.umn.edu
Scot D. Rassat

Pacific Northwest National Laboratory

P.O. Box 999, MSIN K6-28

Richland, WA 99352

509-372-1861 (phone)

509-372-1861 (fax)

scot.rassat@pnl.gov

Michael A. Lilga

Pacific Northwest National Laboratory

P.O. Box 999, MSIN K8-93

Richland, WA 99352

509-375-4354 (phone)

509-372-4732 (fax)

mike.lilga@pnl.gov

Graduate Students

Gregory Anderson

Marcia Toline Giacomini 


\section{Research Objective}

The general aim of this project is to design and prepare new electroactive ion-exchange (EaIX) materials that can be used to remove the radioactive components from high-level radioactive waste (HLW) at U.S. Department of Energy (DOE) sites nationwide. The specific objective is to develop and investigate redox-active polymers, such as polyvinylferrocene (PVF), that can be used to remove pertechnetate $\left(\mathrm{TcO}_{4^{-}}\right)$ion from $\mathrm{HLW}$. Electroactive materials are an important class of materials for this application because they can minimize or eliminate secondary waste streams associated with HLW processing, thereby reducing the costs of environmental cleanup.

The technologies currently available for treatment and disposal of approximately 90 million gallons of HLW at the DOE Savannah River Site, Idaho National Engineering and Environmental Laboratory, and Hanford Site are neither cost-effective nor practical. Processes to separate the HLW constituents from the low-level waste (LLW) fraction are required to reduce the volume of waste that must be treated and disposed of and to reduce the cost of treatment and disposal. Use of EaIX materials, conjoined with the use of porous membranes that also are under development, can significantly reduce or eliminate secondary wastes associated with more traditional ion-exchange or solvent extraction technologies and, thus, can help improve the effectiveness and reduce the cost of DOE's waste treatment and disposal efforts.

Beyond its importance as a cost issue, separation of $\mathrm{TcO}_{4^{-}}$from $\mathrm{HLW}$ also addresses a critical environmental issue. The most common isotope of technetium $\left({ }^{99} \mathrm{Tc}\right)$ has an extremely long half-life of 210,000 years. Rapid development of advanced methods to remove and separate this long-lived radioactive isotope is important because most of the technetium in the DOE HLW probably is in the form of $\mathrm{TcO}_{4^{-}}$, which is highly mobile in soils and groundwater. This project is focused on anion separation and, in particular, the selective separation of $\mathrm{TcO}_{4}$ - from a solution containing excess $\mathrm{NO}_{3^{-}}$. The results of this research can be used to also design EaIX materials to remove other anions.

\section{Research Progress and Implications}

This report summarizes work completed in the first 40 months of a 6-year project. During the first 3 years of the project, we addressed critical issues surrounding the use of PVF as an electroactive material for selective separation of $\mathrm{TcO}_{4^{-}}$from $\mathrm{HLW}$. These issues were concerned with primarily 1) the generally lower molecular weight of PVF polymers that were obtained from conventional synthetic methods and 2) the inability of these polymers to withstand alkaline $\mathrm{pH}$ conditions.

We have been able to obtain PVF polymers with $\bar{M}_{w}=1.1 \times 10^{3} \mathrm{kD}$, which is significantly higher than the $5.0 \times 10^{3} \mathrm{kD}$ weights that can be obtained using conventional syntheses. 
Preparation of higher molecular weight polymers is important because our studies showed that these materials would delaminate readily from electrode surfaces, especially when an oxidizing potential was reached. The delamination issue essentially has been eliminated with the new materials.

The other issue we addressed was the stability of these polymers under alkaline conditions. Ferrocene and its derivatives are generally stable in alkaline solutions, but once the metal center is oxidized to give the ferrocenium moiety, the metallocene rapidly decomposes. Metallocenes can be made stable in alkaline solution by dialkylation of the cyclopentadienyl rings so that the alkyl groups do not possess ionizable protons on the carbon directly attached to the metallocene ring. Most of our studies have focused on the preparation of tert-butyl derivatives of ferrocene. These functionalized polymers exhibit enhanced resistance to decomposition under alkaline conditions as evidenced in their cyclic voltammograms obtained in $0.5-\mathrm{M} \mathrm{NaOH}$ solution. An additional benefit is probably conferred on selectivity of the polymers for $\mathrm{TcO}_{4^{-}}$as the greater hydrophobicity around the alkylated ferrocene center favors interaction with anions that have lower hydration energies.

Characterization of the $\mathrm{ReO}_{4^{-}}$-doped PVF films by x-ray absorption near edge structure (XANES) may indicate that $\mathrm{ReO}_{4^{-}}$interacts with the Fe centers in the PVF polymers, as there appears to be perturbation of the ferrocenium molecular orbitals.

Additional studies initiated in the past 12 months have focused on the use of polymers to prepare electroactive membranes and on the preparation of new materials. For ion separation, membrane-based separation processes are more desirable than ion-exchange processes for several reasons: 1) no periodic downtime occurs (e.g., the separation medium need not be regenerated), 2) no cross-contamination occurs (i.e., entrained fluid is always in an ion-exchange bed), and 3) less secondary waste is generated (i.e., no rinsing or elution is required). Currently, however, one typically must rely on ion-exchange processes when high selectivity is required. Efficient separations of ions with the same charge, for example, cannot be achieved using conventional membranes. An electroactive membrane prepared as carbon nanotubes coated with PVF has been demonstrated to selectively transport monovalent anions across the membrane. A solution of $\mathrm{NaNO}_{3}$ and $\mathrm{Na}_{2} \mathrm{SO}_{4}$ was shown to selectively transport the $\mathrm{NO}_{3}{ }^{-}$ion across the electroactive membrane. Preparation of iron phenanthroline complexes that are stable under extreme $\mathrm{pH}$ conditions (both acidic and alkaline) has been initiated.

\section{Planned Activities}

During summer 2002, we will undertake further x-ray absorption spectroscopy studies at Brookhaven National Laboratory on $\mathrm{TcO}_{4^{-}}$doped PVF films to development an improved understanding of the interactions between the polymer and $\mathrm{TcO}_{4^{-}}$. Additionally, we will study 
the selectivity and uptake of $\mathrm{TcO}_{4}$ - into these polymers and will undertake further development of the electroactive membrane concept. One primary goal here is to covalently attach the polymers to the carbon nanotubes by November 2002. Also, to speed discovery of a material that is stable under waste tank processing conditions, we will be investigating other electroactive materials, such as the iron phenanthroline complexes.

\section{Information Access}

\section{Invited presentations}

Hubler TL. 2001. Separating and Sensing the Pertechnetate Ion: Use of Electroactive Vinylferrocene-Based Polymers for Separations and Smart Materials for Spectroelectrochemical Detection of $\mathrm{TcO}_{4}{ }^{-} .9^{\text {th }}$ International Symposium on Macromolecule Metal Complexes, Brooklyn, New York, August 2001.

Hubler TL. 2001. Separating and Sensing the Pertechnetate Ion: Use of Electroactive Vinylferrocene-Based Polymers and Smart Materials for Spectroelectrochemical Detection of $\mathrm{TcO}_{4}{ }^{-} .56^{\text {th }}$ Northwest Regional Meeting of the American Chemical Society, Seattle, Washington, June 2001.

\section{Publication}

Balasubramanian M, HS Giacomini, HS Lee, J McBreen, and JH Sukamto. 2002. X-Ray Absorption Studies of Poly(vinylferrocene) Polymers for Anion Separation. Accepted for publication, J. Electrochem. Soc. 2002. 